\title{
Gelatin Template Synthesis of Aluminum Oxide and/or Silicon Oxide Containing Micro/Mesopores Using the Proteic Sol-Gel Method
}

\author{
Amanda Sayure Kasuya de Oliveira, Adriana Perpetua Figueiredo Paulista, \\ Ana Ellen Valentim de Alencar, and Tiago Pinheiro Braga \\ Laboratório de Peneiras Moleculares (LABPEMOL), Universidade Federal do Rio Grande do Norte, Campus Universitário, \\ 59078-970 Natal, RN, Brazil
}

Correspondence should be addressed to Tiago Pinheiro Braga; tiagoquimicaufrn@gmail.com

Received 14 May 2017; Accepted 30 August 2017; Published 12 October 2017

Academic Editor: Ping Xiao

Copyright (C) 2017 Amanda Sayure Kasuya de Oliveira et al. This is an open access article distributed under the Creative Commons Attribution License, which permits unrestricted use, distribution, and reproduction in any medium, provided the original work is properly cited.

\begin{abstract}
Aluminum oxide and/or silicon oxide-based supports were synthesized by proteic sol-gel method. The characterization was performed through the analysis of TG, XRD, FTIR, SEM, and $\mathrm{N}_{2}$ physisorption. The XRD diffractograms showed an amorphous material profile. TG results indicate the total liberation of the organic and inorganic material in the calcination temperature used, occurring in different mass loss range. This piece of information was reaffirmed by the FTIR spectra, which presented characteristic bands of gelatin structure before calcinations which disappear in the spectrum of the solid after calcinations, indicating the loss of organic matter from gelatin after heat treatment. The spectra exhibited M-O stretching vibration at low wavenumbers after calcinations related to metal oxides. The acquired images by SEM suggest the obtaining of a highly porous material with very different characteristics depending on the composition of the support. The $\mathrm{N}_{2}$ isotherms indicate the presence of a micro/mesoporous oxide with interesting textural properties, particularly for the supports containing aluminum and silicon oxide. The ethanol dehydration results showed greater selectivity to diethyl ether compared to ethylene. From the reaction data, the following order of acid strength was obtained: $2 \mathrm{Si}-\mathrm{Al}>\mathrm{Si}-2 \mathrm{Al}>\mathrm{Si}-\mathrm{Al}>\mathrm{Al}$, which is related to the $\mathrm{Si}-\mathrm{Al}$ ratio.
\end{abstract}

\section{Introduction}

Catalytic supports are an important class of materials which, as their name implies, fix the active sites on the solids surface in order to improve their different physicochemical properties [1-3]. In general, supports are used, since they allow obtaining a high specific surface area, lead to adequate porosity, provide appropriate acidity and/or basicity, and tolerate elevated temperatures without suffering significant degradation (high thermal conductivity); such characteristics directly affect the catalytic performance (activity, selectivity, and stability) on certain specific reactions [4-8]. The catalytic supports most commonly used in the chemical industry are based on activated carbon, zeolites, molecular sieves, clays, alumina, and/or silica, among others [9-21].
The literature reports various methods for preparation of catalytic supports, such as conventional sol-gel [22, 23], polymeric precursor $[21,24]$, hybrid spheres $[25,26]$, and coprecipitation $[27,28]$. Many of the existing techniques have a considerable cost and take significant time and typically use precursors from nonrenewable sources compared to the proteic sol-gel route proposed here, which uses gelatin from porcine skin as organic precursor (renewable source) and aluminum nitrate and/or tetraorthosilicate (TEOS) as inorganic precursors. It has given enough emphasis in the synthesis of metal oxides and alloys containing nanoparticles with interesting magnetic and optical properties using the proteic sol-gel route [29-33]; however, the synthesis of porous supported materials with potential applications in catalysis still needs to be studied from the gelatin precursor. 
Gelatin is defined as partially hydrolyzed collagen, where the basic unit comprises a protein chain of about 1050 amino acids. The conversion of the collagen into gelatin requires the breaking of hydrogen bonds, stabilizing the triple helix, and thereby determining the random configuration of gelatin. The composition of the gelatin is essentially formed by $84-90 \%$ protein, $8-12 \%$ water, and $2-4 \%$ of mineral salts. The proteic denomination for the synthesis route is due to large protein percentage [34-36]. Figure 1 illustrates the general structure of the gelatin. Gelatin is an important functional biopolymer widely used in foods to improve elasticity, consistency, and stability and in cosmetic and pharmaceutical industries $[37,38]$. However, its application as organic precursor (biotemplate) in the synthesis of porous catalysts remains an open research theme. It is important to emphasize that the functional groups of the gelatin may act as an excellent complexing agent of metallic cations such as $\mathrm{Al}^{3+}$ or $\mathrm{Si}^{4+}$, which is very interesting during the synthesis of metal oxide catalysts with high metallic dispersion and porosity.

Zarai et al. [38-40] reported that the annual world output of gelatin increased to 326,000 tonnes with the highest source being pigskin (46\%), followed by bovine hides (29.4\%), bones (23.1\%), and other sources $(1.5 \%)$, and is expected to reach 450.7 kilotons in 2018, growth of 3.73\% from 2012 to 2018. Consequently, tons of pork skin are discarded, which may be used to produce gelatin, an important organic precursor (template) during the synthesis of the proteic sol-gel method.

The use of organic precursors in the synthesis of catalysts, as gelatin, allows having some control over the metallic dispersion, morphology, and particle size and directly affects the textural, morphological, and structural properties of the final material $[25,41]$, which are essential characteristics in the efficiency of catalytic processes. Thus, the present work shows the bioinspired synthesis and characterization of catalytic supports containing aluminum oxide and/or silicon using an alternative synthetic methodology from gelatin, which is efficient and of low cost.

\section{Experimental}

2.1. Support Preparation. The synthesis of five samples, denoted by $2 \mathrm{Si}-1 \mathrm{Al}, 1 \mathrm{Si}-2 \mathrm{Al}, 1 \mathrm{Si}-1 \mathrm{Al}, \mathrm{Al}$, and $\mathrm{Si}$, was performed by the proteic sol-gel method using porcine gelatin as organosoluble precursor. The numbers represented mean the molar ratio between $\mathrm{Al}$ and $\mathrm{Si}$. $\mathrm{Al}$ and $\mathrm{Si}$ are the samples containing pure aluminum oxide and pure silicon oxide, respectively.

The different solids were prepared based on the different steps in the flow chart of Figure 2. For all samples, the required mass of gelatin in distilled water (enough water to dissolve all the gelatin) was first dissolved in a beaker under constant agitation and the appropriate mass of aluminum nitrate and/or tetraethylorthosilicate was concomitantly dissolved using a magnetic stirrer. After that, the inorganic solutions were added to the gelatin in order to drive the complexation process and the formation of a xerogel. The ratio by weight between the organic and inorganic was maintained at $1: 1$ for the various samples.
Subsequently, the formed xerogel, as a result of the interaction between the organic and inorganic material (hybrid material), was kept at $110^{\circ} \mathrm{C}$ in an oven for two days ( $48 \mathrm{~h}$ ) to dry the samples. Finally, after being removed from the oven, the dried samples were macerated, placed in a porcelain crucible, and calcined at $700^{\circ} \mathrm{C}$ for $2 \mathrm{~h}$ in a muffle furnace ZEZIMAQ model N1100 with a heating rate of $4^{\circ} \mathrm{C} / \mathrm{min}$ to obtain the formation of metal oxides $\left(\mathrm{Al}_{2} \mathrm{O}_{3}\right.$ and/or $\left.\mathrm{SiO}_{2}\right)$.

2.2. Support Characterization. Thermogravimetric analysis (TG) was performed in equipment SDTQ600 model (TA instruments), using an alumina crucible with $5 \mathrm{mg}$ of samples, air flow $(50 \mathrm{~mL} / \mathrm{min})$, and a heating ramp of $25^{\circ} \mathrm{C}$ to $800^{\circ} \mathrm{C}$ with a heating rate of $10^{\circ} \mathrm{C} / \mathrm{min}$ in order to observe weight loss with temperature variation and the minimum temperature for complete decomposition/oxidation of the gelatin.

The X-ray diffraction analyses were carried out on a Bruker D2 Phaser diffractometer using $\mathrm{CuK} \alpha$ radiation $(\lambda=$ $1,54 \AA$ ) with an Ni filter, with step of $0,02^{\circ}$, current of $10 \mathrm{~mA}$, voltage of $30 \mathrm{kV}$, using a Lynxeye detector to determine the crystal structure of the synthesized solid. The analysis was performed with angle $2 \theta$, ranging from 10 to 90 degrees.

FTIR analyses were performed to determine stretches present in the samples before and after calcination. The range of wavenumber was 550 to $4000 \mathrm{~cm}^{-1}$ for transmittance using a spectrometer Perkin Elmer's spectrum 65 model in order to confirm the elimination of the gelatin after calcination and the formation of a hybrid material before calcination.

The scanning electron microscopy was used to visualize the morphology and the visual porosity of the materials. SEM was performed with a Hitachi Tabletop Microscope TM-3000, Hitachi. The accelerating voltage was $5-15 \mathrm{kV}$ and different magnifications were applied ( 15 to $30000 \mathrm{x}$ ).

The measurements were performed at a temperature of $77 \mathrm{~K}\left(-196^{\circ} \mathrm{C}\right)$ in a gas adsorption analyzer ASAP 2020 Physisorption/Micromeritics model, to obtain the textural properties of the support. Prior to analysis, the samples were degassed under vacuum at $200^{\circ} \mathrm{C}$ for $2 \mathrm{~h}$. This treatment aims to remove moisture and $\mathrm{CO}_{2}$ from the solid surface. From the obtained isotherms, the specific surface area, volume, and pore diameter values were extracted.

The acidity of the different samples was evaluated by model ethanol dehydration reaction. The reactions were performed in a fixed bed flow reactor, using $0.150 \mathrm{~g}$ of solid at $250^{\circ} \mathrm{C}$. Before the reaction, the supports were activated under a stream of pure $\mathrm{N}_{2}$ during $1 \mathrm{~h}$ at atmospheric pressure and $350^{\circ} \mathrm{C}$. A mixture containing $\mathrm{N}_{2}$ and vapour of ethanol (at total flow of $30 \mathrm{~mL} / \mathrm{min}$ ), which flowed through the reactor, was established by $\mathrm{N}_{2}$ flow through a saturation system (flask) containing ethanol at $25^{\circ} \mathrm{C}$. The mixture was analyzed by gas chromatography equipped with a flame ionization detector (FID) and capillary column during reaction.

\section{Results and Discussion}

3.1. Thermogravimetric Analysis (TG). Thermogravimetric analysis (Figure 3) shows the weight loss with increasing temperature. Three major regions of weight loss were observed, 


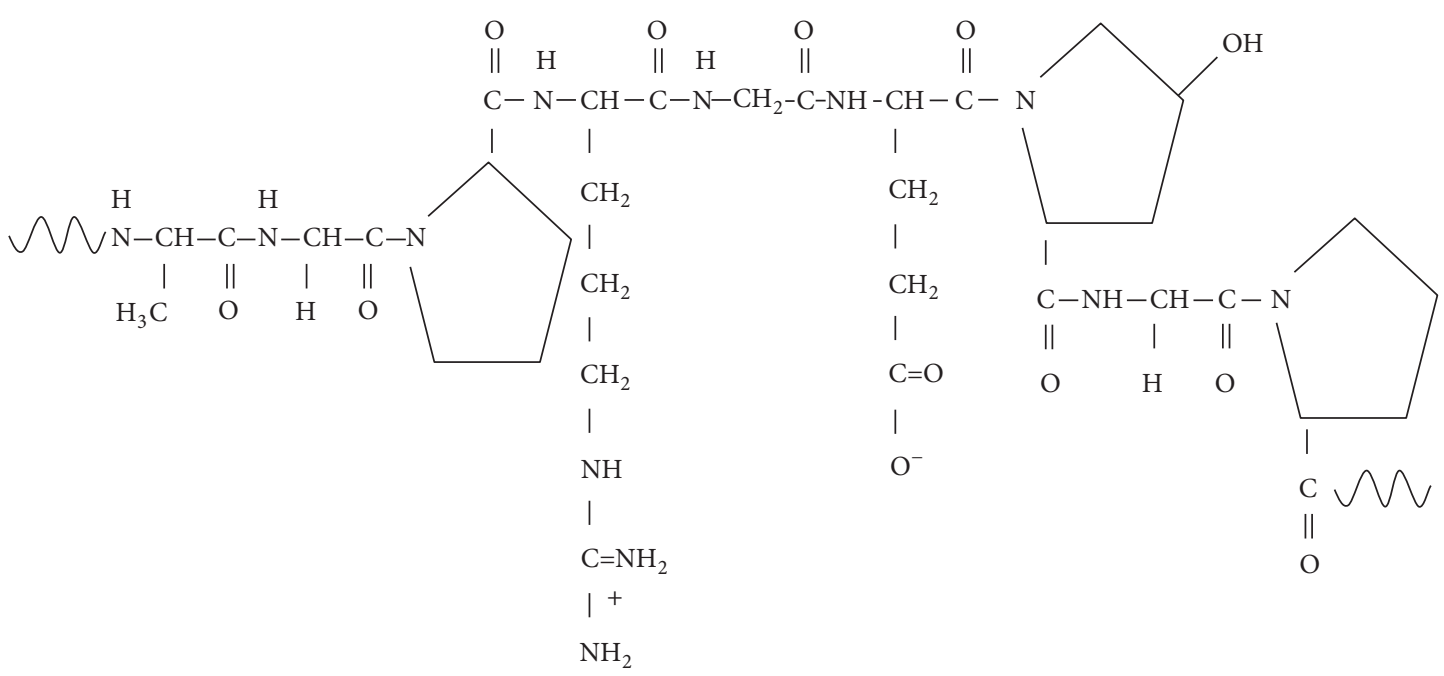

FIgURE 1: General structure of the gelatin.

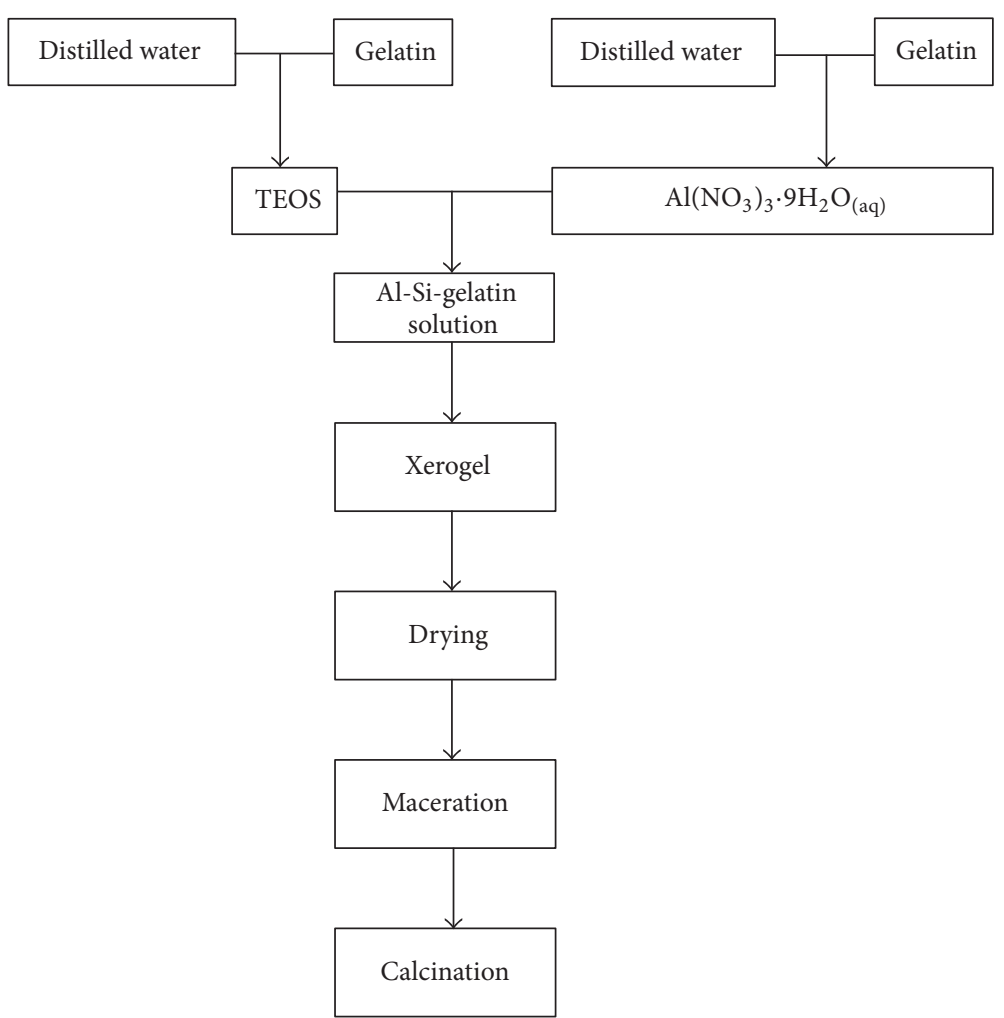

FIGURE 2: Flowchart related to synthesis using the proteic sol-gel method.

except for the pure Si support which showed only two regions. The first region between 30 and $150^{\circ} \mathrm{C}$ shows the loss of physisorbed water. This range of $6.5,7.9,7.0,4.7$, and $3.6 \%$ of mass loss for the samples $\mathrm{Si}, 2 \mathrm{Si}-\mathrm{Al}, \mathrm{Si}-2 \mathrm{Al}, \mathrm{Si}-\mathrm{Al}$, and $\mathrm{Al}$, respectively, was observed. The second region between 150 and $240^{\circ} \mathrm{C}$ is possibly due to thermal decomposition of nitrate and TEOS (inorganic precursors) as well as the initiation of decomposition of organic material (porcine gelatin). In this second temperature range, 51.0, 17.1, 17.2, 18.2, and $14.4 \%$ of mass loss for the solids $\mathrm{Si}, 2 \mathrm{Si}-\mathrm{Al}, \mathrm{Si}-2 \mathrm{Al}, \mathrm{Si}-\mathrm{Al}$, and $\mathrm{Al}$, respectively, are observed. The third weight loss range between 240 and $680^{\circ} \mathrm{C}$ probably concerns the gelatin oxidation, mainly in the form of $\mathrm{CO}$ and $\mathrm{CO}_{2}$ and other gases in different regions of the solid. The third region shows the largest mass loss with values of $60.4,28.6,32.4$, and 33.7 for the supports $2 \mathrm{Si}-\mathrm{Al}$, $\mathrm{Si}-2 \mathrm{Al}, \mathrm{Si}-\mathrm{Al}$, and $\mathrm{Al}$, respectively. Specifically for sample $\mathrm{Si}$, the second and third range occurred in single event between 215 and $530^{\circ} \mathrm{C}$, indicating that the presence of aluminum 


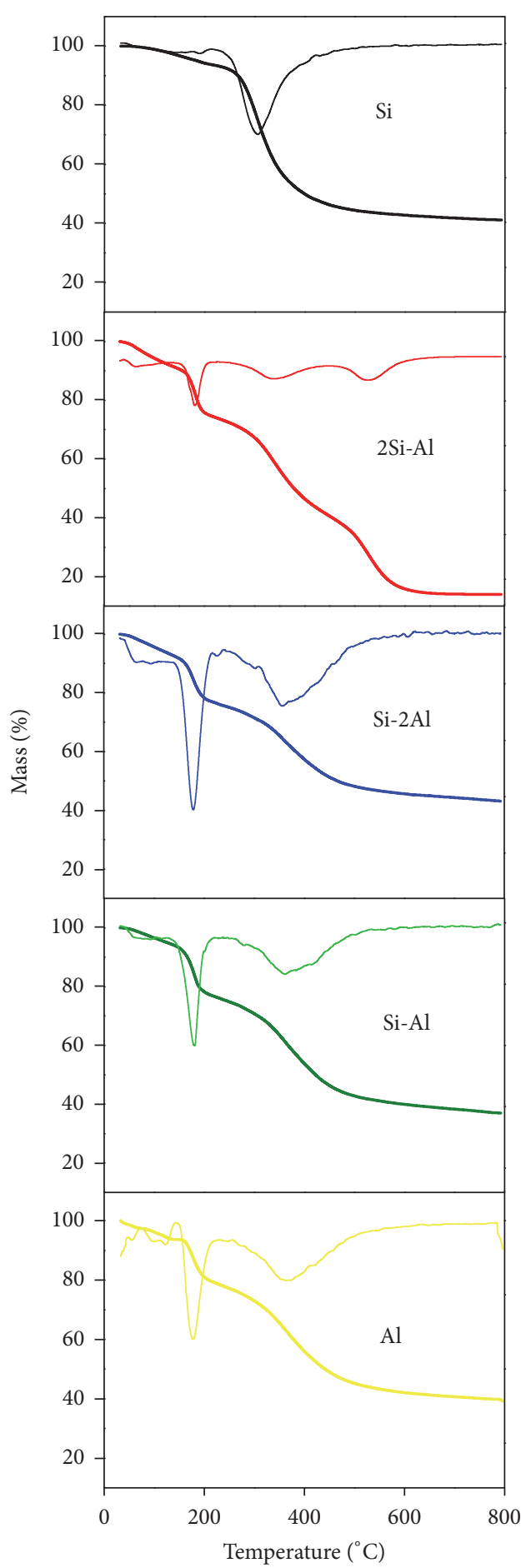

FIGURE 3: Thermogravimetric analysis for the solids, TG and DTG.

nitrate causes changes in thermal decomposition properties, since $\mathrm{Al}^{3+}$ in aluminum nitrate and $\mathrm{Si}^{4+}$ in TEOS interact differently with the functional groups present in the gelatin.

The complete elimination of the organic matter occurs at approximately $680^{\circ} \mathrm{C}$, after any more weight loss was not observed, indicating that this is the minimum temperature required for complete decomposition/oxidation of organic and inorganic material. Finally, after $680^{\circ} \mathrm{C}$, this leads to the formation of aluminum oxide and/or silicon oxide with high porosity due to the cavities created by the absence of gelatin, which was also evidenced by the color change, comparing the obtained samples after drying and after calcination. Thus, all samples were calcined at $700^{\circ} \mathrm{C}$ to ensure the complete release of the organic matter and formation of the metal oxides $\left(\mathrm{Al}_{2} \mathrm{O}_{3}\right.$ and $\left.\mathrm{SiO}_{2}\right)$.

From the results of thermal analysis, one can note a variation of mass loss temperatures depending on the $\mathrm{Si}-\mathrm{Al}$ ratio and for pure $\mathrm{Si}$ and $\mathrm{Al}$. This shift in the temperature event may influence the morphology of the samples (volume and pore diameter) after the thermal treatment, which will be confirmed by SEM and $\mathrm{N}_{2}$ physisorption analyses. Particularly, the pure Si sample may have different porosity due to discrepancy in the thermal analysis profile compared to other supports.

3.2. X-Ray Diffraction (XRD). The XRD patterns of the different supports are presented in Figure 4. The diffractograms for the samples containing pure silica show an amorphous solid profile with a very broad peak at low angle $2 \theta$, typical for this type of material.

Similarly, the aluminum oxide-based samples also demonstrated an amorphous material behavior. However, the formation of extremely small crystallites and/or a large number of defects (microstrain), which hinder their identification by XRD, may not be neglected. The synthetic route employed leads to formation of nanocrystallites with very small size due to the use of organic biopolymer, which probably acts as a physical barrier, minimizing the crystallites sintering during the calcination step, and this may compromise the identification of crystalline phases by XRD (well-defined peaks). The identification of profiles similar to those shown in Figure 4 indicates the formation of metal oxides with high dispersion, which may be interesting for catalytic supports.

3.3. Fourier Transform Infrared Spectroscopy (FTIR). The different spectra of the samples before calcination (after drying) and after calcination are shown in Figures 5(a) and 5(b), respectively. For comparison, the spectrum of pure gelatin is present in Figure 5(a). The spectra before calcination presented characteristic organic functional groups of the gelatin $(\mathrm{C}=\mathrm{O}, \mathrm{C}-\mathrm{N}-\mathrm{H}, \mathrm{C}-\mathrm{H}$, etc.). A band is observed around $1630 \mathrm{~cm}^{-1}$ related to the $\mathrm{C}=\mathrm{O}$ vibrational mode, the presence of C-N-H stretch in the region of $1500 \mathrm{~cm}^{-1}$, a C-H stretching absorptions near $1300 \mathrm{~cm}^{-1}$, and $\mathrm{C}-\mathrm{O}$ stretch at around $1000 \mathrm{~cm}^{-1}$. Therefore, these are functional groups which have a high probability to complex with metallic cations such as $\mathrm{Al}^{3+}$ and $\mathrm{Si}^{4+}[42,43]$.

Comparing the obtained values of stretches for samples after drying with the pure gelatin, a variation of wavenumber and band intensity for solid after complexation (xerogel formation) related to the original gelatin was noted, probably indicating that the metals $\left(\mathrm{Al}^{3+}\right.$ and $\left.\mathrm{Si}^{4+}\right)$ were complexed with the functional groups of gelatin. This piece of information confirms the formation of a hybrid material during the 


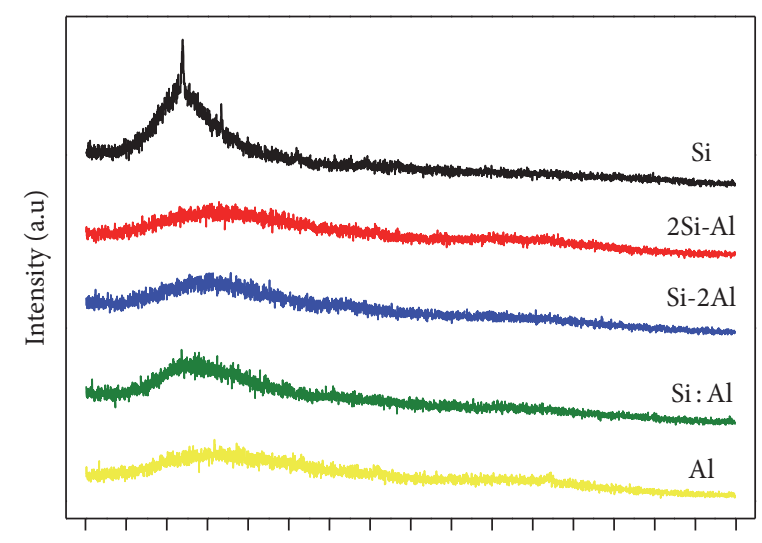

$\begin{array}{lllllllllllllllll}10 & 15 & 20 & 25 & 30 & 35 & 40 & 45 & 50 & 55 & 60 & 65 & 70 & 75 & 80 & 85 & 90\end{array}$

$2 \theta\left(^{\circ}\right)$

FIgURE 4: X-ray diffractograms of the different supports.

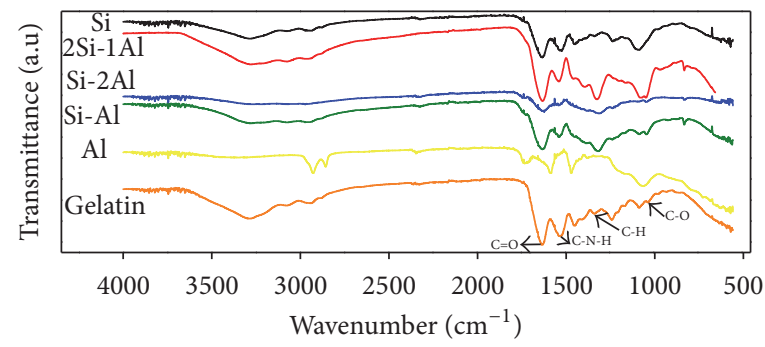

(a)

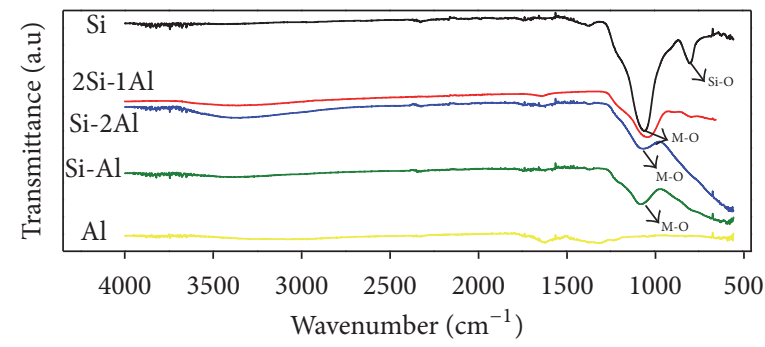

(b)

FIGURE 5: Fourier transform infrared spectroscopy results. (a) Before calcination; (b) after calcination.

first stage of synthesis. The uniform dispersion of the metal ions in the gelatin radicals due to the complexation in specific positions (functional groups of gelatin) is essential to obtain a widely dispersed metal oxide after calcination, as observed by X-ray diffraction (Figure 4).

However, after calcination, as expected, no more stretches were observed concerning the organic material, whereas gelatin was released during the heat treatment $\left(700^{\circ} \mathrm{C}\right.$ in air), according to the TG results (Figure 3). Low wavenumbers vibrations related to the metal oxides were seen in the FTIR spectra after calcination ( $\mathrm{Si}-\mathrm{O}$ or $\mathrm{Al}-\mathrm{O}$ ). Therefore, the confirmation by TG and FTIR, of the complete liberation of the gelatin during calcinations, is a strong indication that there was the formation of a very porous support due to the formed vacancy during the degradation/oxidation of organic material, which will be confirmed by SEM and $\mathrm{N}_{2}$ physisorption isotherms.

3.4. Scanning Electron Microscopy (SEM). The images presented in Figure 6 show the morphology of different supports obtained by SEM. It is important to highlight that the pore size detected by the images exposed in Figure 5 has a size well above the value compared with pore size determined by $\mathrm{N}_{2}$ adsorption/desorption isotherms (Figure 6); however, this provides an indication that indeed it is a highly porous material, since it showed a sponge-like morphology which resulted in the high surface porosity.

This morphology is justified by the synthesis method used (proteic sol-gel), since a biotemplate (gelatin) was used in the preparation of different supports, which allows uniform distribution of metallic cations $\left(\mathrm{Al}^{3+}\right.$ or $\left.\mathrm{Si}^{4+}\right)$ in the organic matrix. These samples during thermal treatment at high temperature (controlled heating) suffer the gradual decomposition of organic matter (gelatin) in parallel with the formation of highly dispersed metal oxides (preservation of hybrid material dispersion), according to thermal analyses results (Figure 3), XRD diffractograms (Figure 4), and FTIR spectra (Figure 5(b)), generating cavities as a result of its elimination, which are clearly visible in the SEM images.

Visually by the images of Figure 6, it was seen that the pores characteristics vary greatly depending on the composition and $\mathrm{Si} / \mathrm{Al}$ ratio. Interestingly, the support with pure silicon (Figure 6(e)) presented an aspect of a nonporous material or with very low porosity compared to the other solids which may be related to the different thermal decomposition process presented in TG results. However, the sample with higher amount of silicon oxide (2Si-1Al) shows pores with larger size compared to the solids with greater amount of aluminum oxide, indicating that the Si/Al ratio influences the final porosity. Thus, it is clear from TG and SEM images that the way that gelatin, aluminum nitrate, 

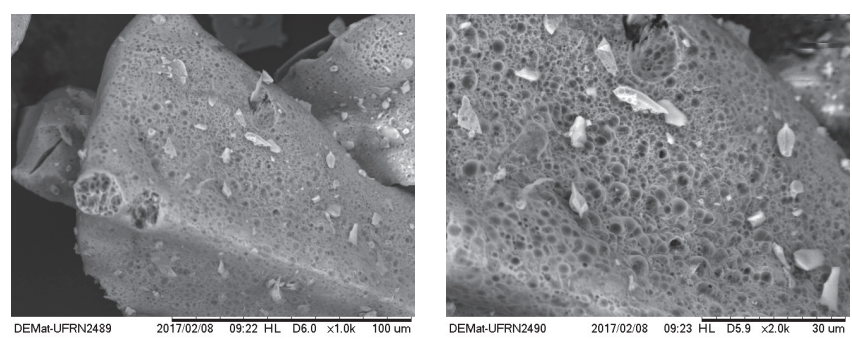

(a)
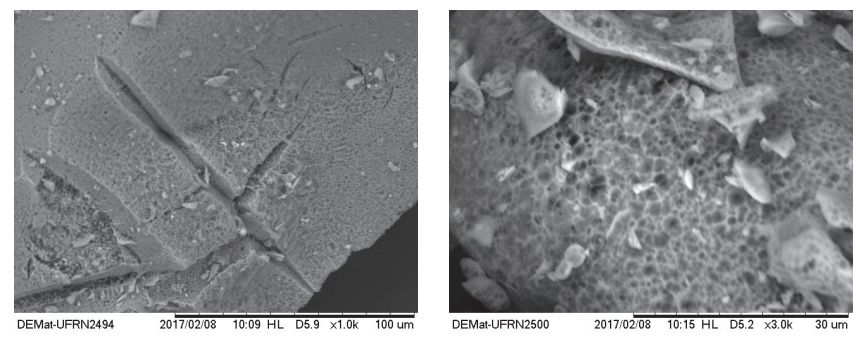

(c)

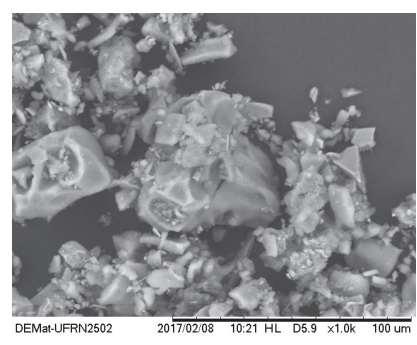

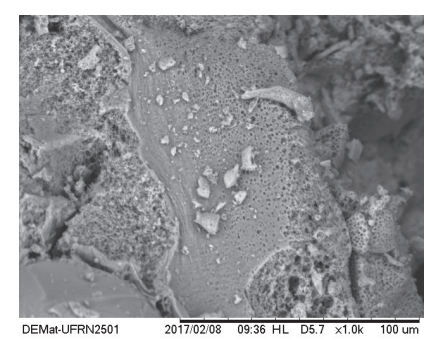

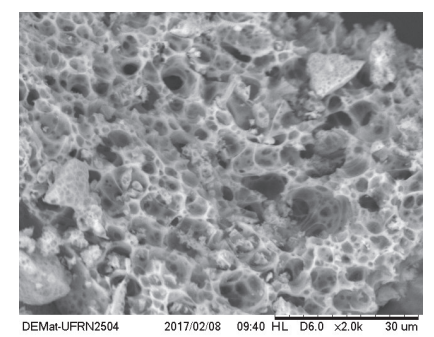

(b)
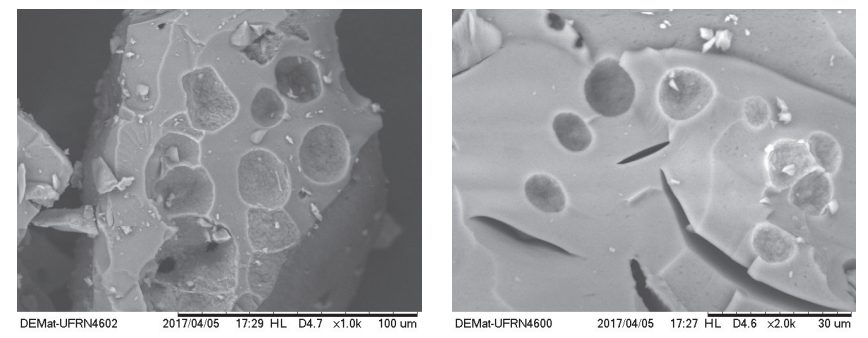

(d)

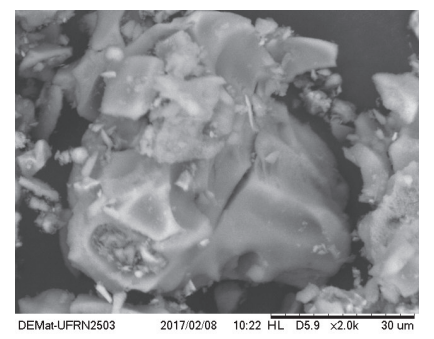

(e) and/or TEOS are decomposed leads to results of different porosities. On the other hand, $\mathrm{N}_{2}$ adsorption/desorption isotherms analysis is needed to confirm these assumptions.

3.5. $\mathrm{N}_{2}$ Physisorption Analysis. The $\mathrm{N}_{2}$ adsorption/desorption isotherms of different synthesized supports are presented in Figure 7.

All Al-based isotherms (Al, Si-Al, Si-2Al, and 2Si-Al) have hysteresis loop in the relative pressure region, not occurring reversibility, indicating the presence of mesopores as shown by the pore diameter distribution profile (Figure 7(b)). The same samples (Si-Al, Si-2Al, and 2Si-Al) also indicate the presence of micropores at low relative pressure values. Despite the similarity of these four solids related to the pores characteristics (micro- and mesoporous), it is clear that the $\mathrm{Al}$ support, containing pure aluminum oxide, shows a type $\mathrm{V}$ isotherm while $1 \mathrm{Si}-1 \mathrm{Al}, 1 \mathrm{Si}-2 \mathrm{Al}$, and $2 \mathrm{Si}-1 \mathrm{Al}$ catalysts, containing both aluminum oxide and silicon oxide, have a type IV isotherm. On the other hand, the pure $\mathrm{Si}$ solid presents a type III isotherm, indicating a surface of a nonporous or macroporous solid which is in accordance with SEM images, since Si sample did not present cavities in the microscopy images compared to the other solids.
Furthermore, the solids Si-Al, Si-2Al, and 2Si-Al present a hysteresis loop type $\mathrm{H} 4$, which is often associated with narrow slit-like pores. However, the Al material has a hysteresis type $\mathrm{H} 3$, which is related to the pores with wedges formats, cones, and/or parallel plates. BJH desorption pore distribution curves for the Al-based supports (Figure 7(b)) indicated a narrow distribution of pores (unimodal) in the micro/mesopore range with values between 1.5 and $6.0 \mathrm{~nm}$.

Therefore, based on the profile of the five isotherms (Figure 7(a)) and based on SEM images (Figure 6), it is clearly perceived that the support composition (Si/Al ratio) directly affects the characteristics of pores formed and probably will have an essential role in catalytic activity and selectivity for reactions that are sensitive to porosity.

The surface area, total pore volume, and average pore diameter values of the different supports after calcinations are listed in Table 1. It is noticed that the supports containing only pure aluminum oxide or pure silicon oxide presented smaller surface area compared to the other catalysts (mixed oxides). Therefore, the combination of silicon oxide and aluminum oxide positively affects the catalytic properties of the final material. Therefore, possibly mixed aluminum and silicon 


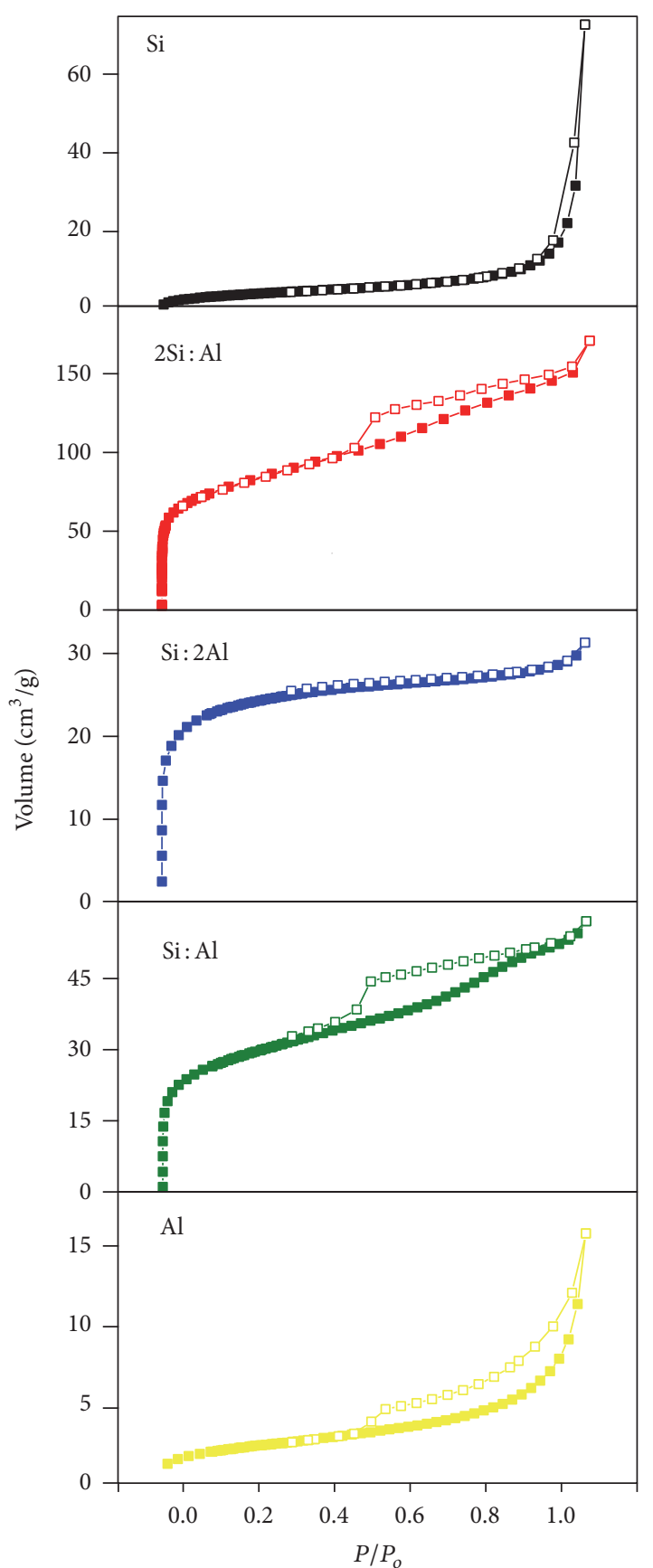

(a)

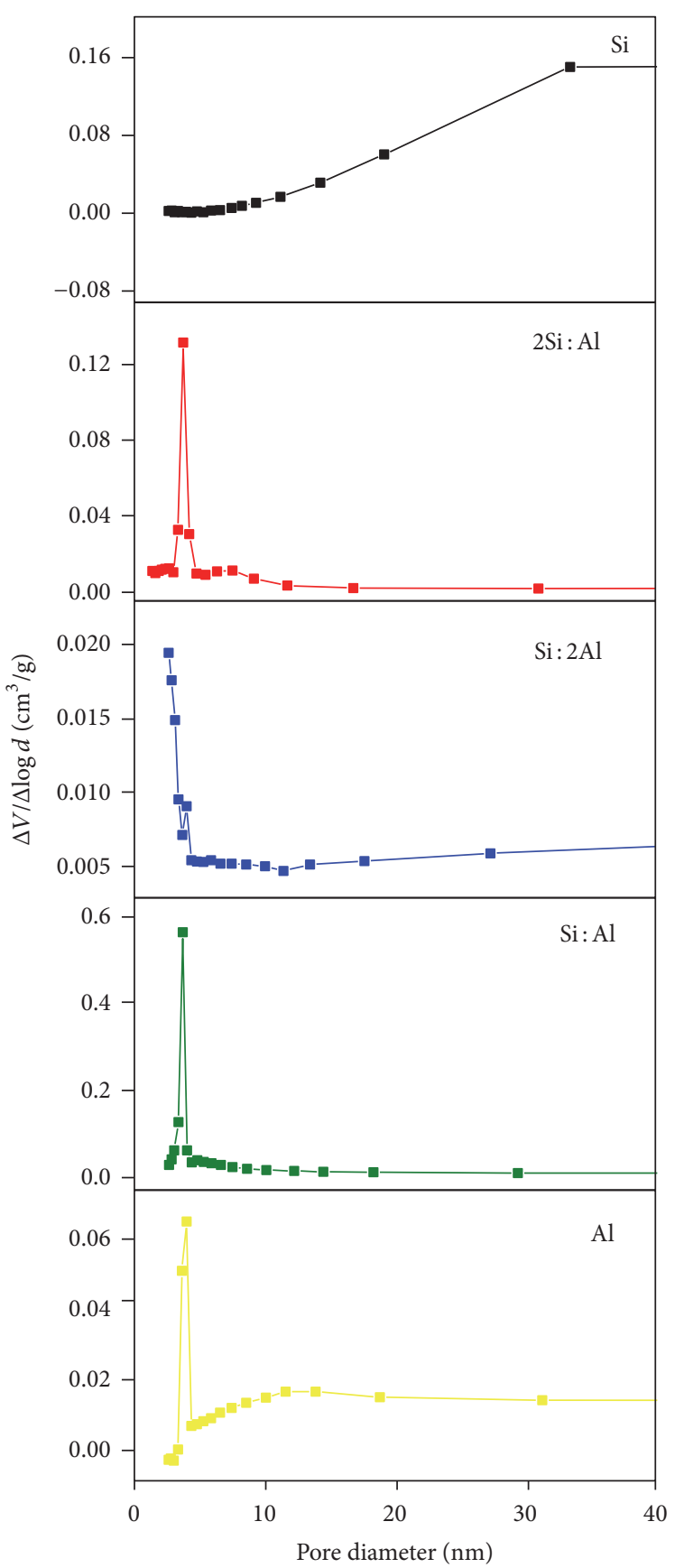

(b)

FIGURE 7: (a) $\mathrm{N}_{2}$ adsorption/desorption isotherms for the different supports. (b) BJH pore size distribution.

oxides will be better catalytic supports compared to pure oxides.

3.6. Acidity from Ethanol Dehydration. Characterization of catalysts by model reactions is rather common to evaluate acid-basic sites strength. The alcohols decomposition is a model reaction to determine the acid-base nature of catalytic materials. It has been reported in the literature that the ethanol decomposition reaction can follow three possible routes: (1) intramolecular dehydration that produces ethylene using acid sites, (2) intermolecular dehydration to generate diethyl ether from acid sites, and (3) alcohol dehydrogenation to produce acetaldehyde using basic sites [44, 45]. Thus, the different supports were tested in ethanol conversion to determine the acidic strength order of the solids (Figure 8).

Figure 8 displays the following initial conversion order (average for the first hour of reaction): $2 \mathrm{Si}-\mathrm{Al}>\mathrm{Si}-2 \mathrm{Al}>$ $\mathrm{Si}-\mathrm{Al}>\mathrm{Al}$. In the first minutes of reaction all active sites 


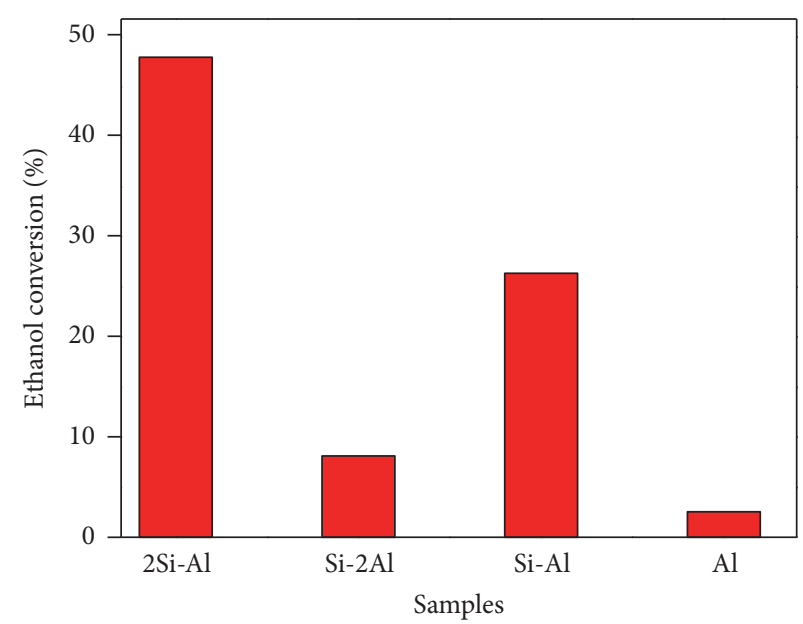

(a)

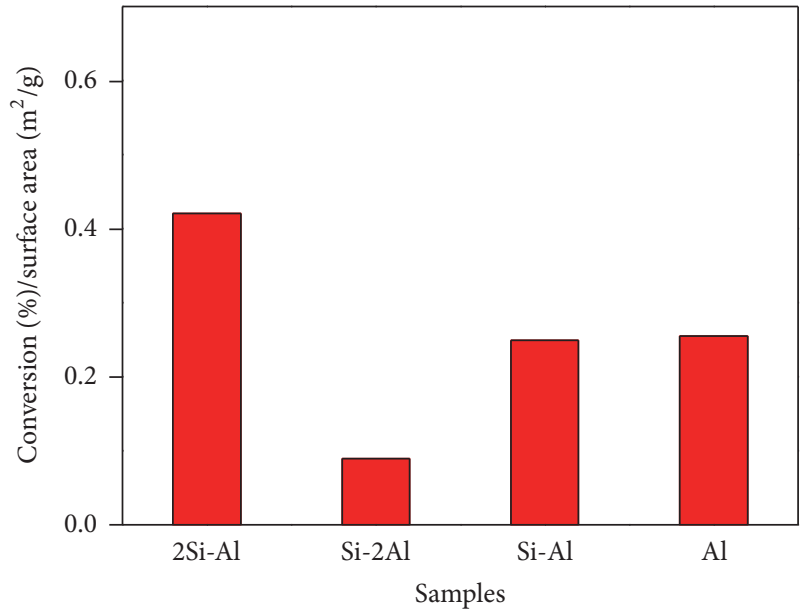

(b)

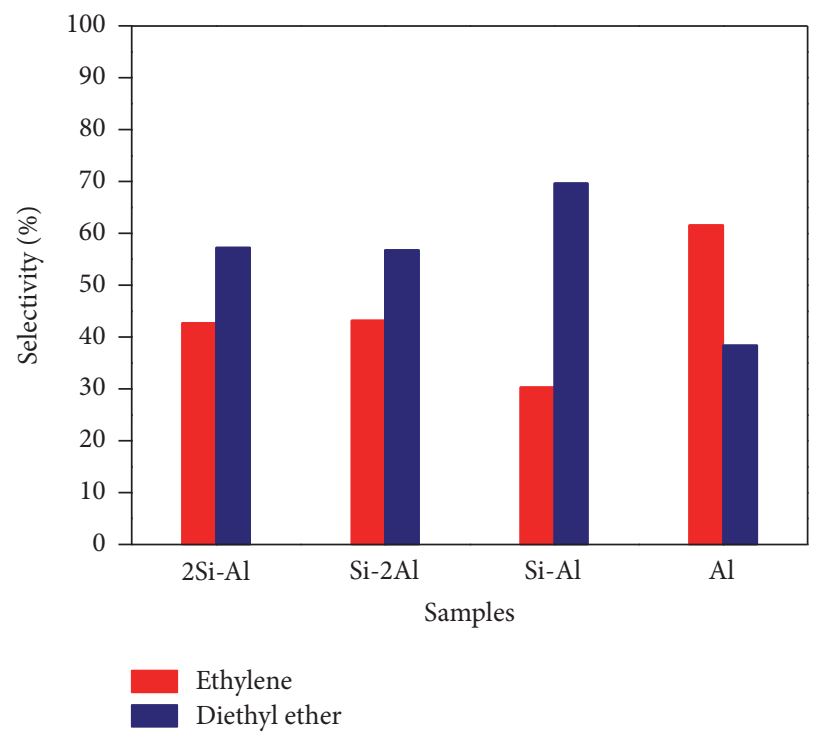

(c)

FIGURE 8: Catalytic tests of the Al- and/or Si-containing catalysts: (a) conversion of ethanol, (b) conversion of ethanol normalized by surface area, and (c) ethylene and diethyl ether selectivity.

TABLE 1: Textural properties of solids. $S$ : specific surface area; $V_{p}$ : pore volume; $D_{p}$ : average diameter of pores.

\begin{tabular}{lccr}
\hline Samples & $S_{\mathrm{BET}}\left(\mathrm{m}^{2} \mathrm{~g}^{-1}\right)$ & $V_{p}\left(\mathrm{~cm}^{3} \mathrm{~g}^{-1}\right)$ & $D_{p}(\mathrm{~nm})$ \\
\hline $\mathrm{Si}$ & 17 & 0.11 & - \\
Si-Al & 294 & 0.27 & 3.5 \\
$\mathrm{Si}-2 \mathrm{Al}$ & 91 & 0.05 & 2.7 \\
$\mathrm{Si}-\mathrm{Al}$ & 106 & 0.09 & 3.8 \\
$\mathrm{Al}$ & 10 & 0.02 & 4.1 \\
\hline
\end{tabular}

are available for ethanol adsorption; thus, the first points are more representative of the total acidity. The selectivity results confirm the presence of acid sites, since only dehydration products (ethylene and diethyl ether) were observed. The presence of basic sites was not identified, since the ethanol dehydration product (acetaldehyde) was not observed.

The higher selectivity to diethyl ether is justified by thermodynamic aspects; considering that the ethanol dehydration to diethyl ether is an exothermic process which is favored, at low temperatures $250^{\circ} \mathrm{C}$ greater selectivity to diethyl ether is expected compared to ethylene (endothermic reaction). Diethyl ether is found very predominant at low temperature and conversion, while ethylene is predominant at high temperature and conversion.

Considering that the dehydration rate is directly related to acidic strength, the solids had the following order of acid strength: $2 \mathrm{Si}-\mathrm{Al}>\mathrm{Si}-2 \mathrm{Al}>\mathrm{Si}-\mathrm{Al}>\mathrm{Al}$ which is directly related to silicon-aluminum ratio. In the case of alumina 


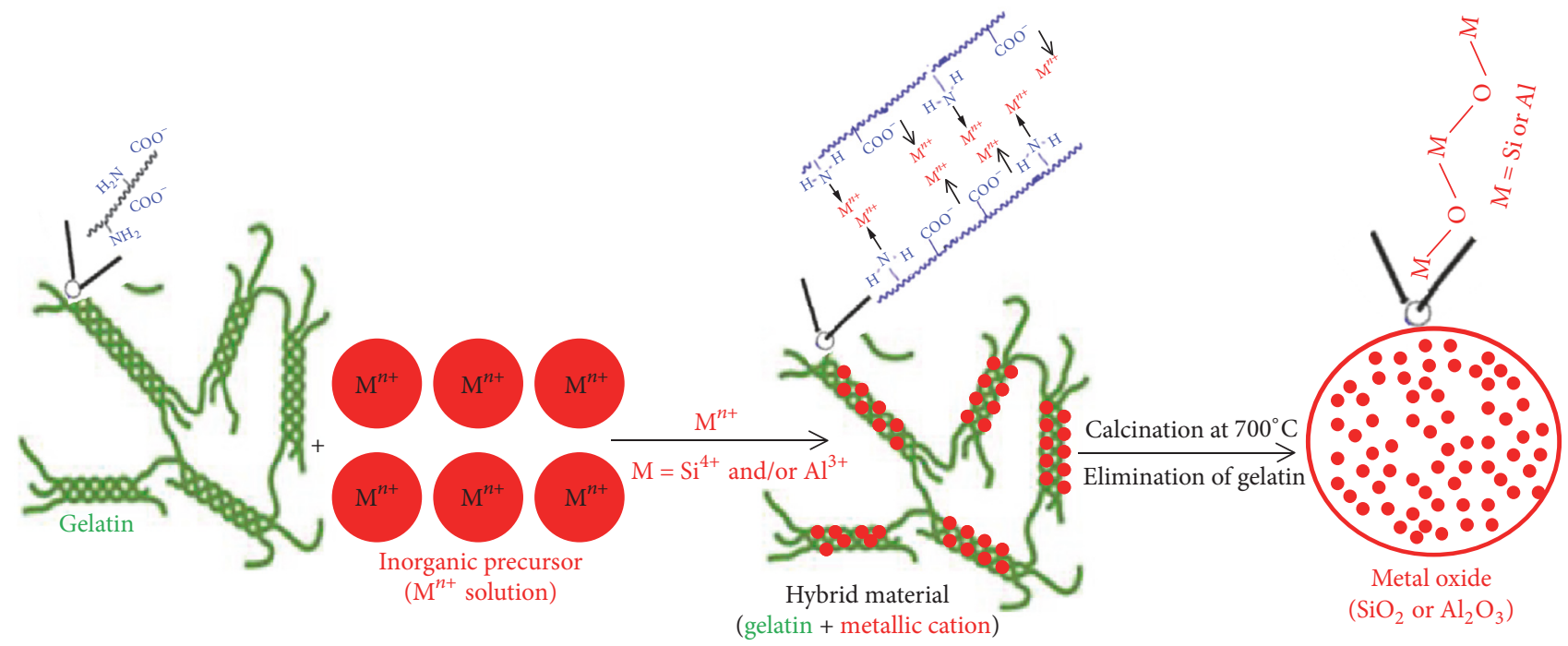

FiguRE 9: Schematic mechanism for the formation of micro/mesoporous aluminum oxide and/or silicon oxide using the gelatin as biotemplate.

and amorphous silica-aluminas, the acidity trend is closely related to their surface area (Table 1); the higher the surface area, the higher the catalytic activity. Therefore, increasing the exposed acid sites and higher ethanol conversion and acidity are obtained. In order to take into account the value of the exposed area in the ethanol conversion, Figure 8(b) presents the conversion values normalized by the surface area from $\mathrm{N}_{2}$ physisorption. In this case, the supports presented the following order of acid strength: $\mathrm{Al} \approx \mathrm{Si}-2 \mathrm{Al}>2 \mathrm{Si}-\mathrm{Al}>\mathrm{Si}$ $\mathrm{Al}$, which represents the acidity per gram of material. Both sequences indicate that increasing the $\mathrm{Si}-\mathrm{Al}$ ratio leads to increased surface area and increases the number of exposed acid sites for the reaction. Thus, the gelatin method leads to the formation of acidic supports where the strength depends on the Si-Al ratio.

The essential role of gelatin (biotemplate) in the formation of micro/mesopores with a high dispersion of metal oxides is illustrated in the scheme of Figure 9. The potential complexing functional groups of the gelatin (amino and carboxylic acid) are responsible for the complexation of metal cations $\left(\mathrm{Al}^{3+}\right.$ and/or $\mathrm{Si}^{4+}$ ), leading to a uniform dispersion of metal cations in the organic matrix (gelatin). The high dispersion is maintained for the metal oxide $\left(\mathrm{SiO}_{2}\right.$ and/or $\mathrm{Al}_{2} \mathrm{O}_{3}$ ) even after calcinations at $700^{\circ} \mathrm{C}$ and concomitantly the formation of nanocrystallites with very small size occurs, since the organic template (organic fraction) acts hindering the sintering/coalescence of the particles (inorganic fractions) during the calcination stage (controlled heating).

The formation of micro/mesopores of $\mathrm{SiO}_{2}$ and/or $\mathrm{Al}_{2} \mathrm{O}_{3}$ is justified by the morphology (spongy-like) and texture (high porosity) of the starting template (gelatin), which are replicated in the hybrid material (xerogel) and subsequently in the final oxide $\left(\mathrm{SiO}_{2}\right.$ and/or $\left.\mathrm{Al}_{2} \mathrm{O}_{3}\right)$ after calcinations. The mechanism for the formation of micro/mesopores with high metal oxides dispersion (Figure 9) is consistent with all characterizations results. Similar polymer template synthesis mechanism of porous oxide was previously described with other templates [25, 41, 46-49].

\section{Conclusions}

Catalytic supports containing aluminum oxide and/or silicon oxide were synthesized through an alternative method, denominated proteic sol-gel, which uses as organic precursor (template) the gelatin from porcine skin. These supports have low cost, are simple, and have efficient methodology beside using an organic precursor from a renewable source, which may be characterized as an environmentally friendly synthesis.

TG analyses showed different mass loss regions with the total release of the organic matter at $680^{\circ} \mathrm{C}$. FTIR spectrum confirmed the formation of a hybrid material due to the interaction between the organic and inorganic compounds which are degraded during calcination. The X-ray results presented profiles of amorphous material, indicating the formation of well dispersed phases with small crystallite size or the presence of materials with large numbers of defects (microstrain).

The images obtained by SEM suggest a morphology that characterizes a material with high porosity, which is influenced by the composition of the support. The $\mathrm{N}_{2}$ physisorption isotherms profiles indicate the formation of a $\mathrm{micro/mesoporous} \mathrm{material} \mathrm{with} \mathrm{interesting} \mathrm{surface} \mathrm{area} \mathrm{for}$ the samples $\mathrm{Si}-\mathrm{Al}, \mathrm{Si}-2 \mathrm{Al}$, and 2Si-Al. Therefore, the presence of silicon oxide combined with aluminum oxide is essential to obtain a catalyst with a higher specific surface area. The mixed oxides showed better textural properties compared to pure oxides.

The model ethanol dehydration reaction confirmed the presence of acidic sites and indicated that the acid strength increases with increasing the Si-Al ratio. The presence of basic sites was not identified, since ethanol dehydrogenation product was not observed. 
Thus, this study indicates that the synthesis method used from gelatin is interesting for catalytic supports preparation containing aluminum oxide and/or silicon oxide, since it presented promising structural, textural, morphological, and acidic properties, which are essential in applications such as heterogeneous catalysts.

\section{Conflicts of Interest}

The authors declare that they have no conflicts of interest.

\section{Acknowledgments}

The authors would like to acknowledge all the members of LABPEMOL, where the experiments and analyses were performed, and technical staff of UFRN for the TGA and FTIR analysis.

\section{References}

[1] M. Schmal, Catálise Heterogênia, Synergia, Rio de Janeiro, Brazil, 2011.

[2] Figueiredo J. L. and Ribeiro F. R., Catálise Heterogénia, vol. 2, Fundação Calouste Gulbenkian, Lisboa, Portugal, 2007.

[3] Z. Ma and F. Zaera, "Heterogeneous catalysis by metals," in Proceedings of the Encyclopedia of Inorganic Chemistry, John Wiley, 2006.

[4] J. Ramirez, T. Klimova, Y. Huerta, and J. Aracil, "Control of porosity and surface area in $\mathrm{TiO} 2-\mathrm{Al} 2 \mathrm{O} 3$ mixed oxides catalytic supports. A statistical approach," Applied Catalysis A: General, vol. 118, no. 1, pp. 73-86, 1994.

[5] A. M. Polcaro, S. Palmas, and S. Dernini, "Role of catalyst characteristics in electrocatalytic hydrogenation: reduction of benzaldehyde and acetophenone on carbon felt/palladium electrodes," Industrial \& Engineering Chemistry Research, vol. 32, no. 7, pp. 1315-1322, 1993.

[6] P. N. Brown, G. G. Jayson, B. Mile, and M. C. Wilkinson, "Activated charcoal cloth as a "support" for copper in the decomposition of formic acid," Carbon, vol. 27, no. 2, pp. 171$176,1989$.

[7] N. Bouchenafa-Saïb, P. Grange, P. Verhasselt, F. Addoun, and V. Dubois, "Effect of oxidant treatment of date pit active carbons used as Pd supports in catalytic hydrogenation of nitrobenzene," Applied Catalysis A: General, vol. 286, no. 2, pp. 167-174, 2005.

[8] A. Michalska, M. Daturi, J. Saussey, I. Nowak, and M. Ziolek, "The role of MCM-41 composition in the creation of basicity by alkali metal impregnation," Microporous and Mesoporous Materials, vol. 90, no. 1-3, pp. 362-369, 2006.

[9] S. Morales-Torres, A. M. T. Silva, F. J. Maldonado-Hódar et al., "Pt-catalysts supported on activated carbons for catalytic wet air oxidation of aniline: Activity and stability," Applied Catalysis B: Environmental, vol. 105, no. 1-2, pp. 86-94, 2011.

[10] B. Meryemoglu, B. Kaya, S. Irmak, A. Hesenov, and O. Erbatur, "Comparison of batch aqueous-phase reforming of glycerol and lignocellulosic biomass hydrolysate," Fuel, vol. 97, pp. 241-244, 2012.

[11] T. Hanaoka, T. Miyazawa, K. Shimura, and S. Hirata, "Effect of Pt particle density on the hydrocracking of Fischer-Tropsch products over Pt-loaded zeolite catalysts prepared using waterin-oil microemulsions," Chemical Engineering Journal, vol. 274, pp. 256-264, 2015.
[12] A. Taheri Najafabadi and F. Taghipour, "Physicochemical impact of zeolites as the support for photocatalytic hydrogen production using solar-activated TiO2-based nanoparticles," Energy Conversion and Management, vol. 82, pp. 106-113, 2014.

[13] H. Balcar and J. Čejka, "Mesoporous molecular sieves as advanced supports for olefin metathesis catalysts," Coordination Chemistry Reviews, vol. 257, no. 21-22, pp. 3107-3124, 2013.

[14] P. Topka, H. Balcar, J. Rathouský, N. Žilková, F. Verpoort, and J. Čejka, "Metathesis of 1-octene over MoO3 supported on mesoporous molecular sieves: The influence of the support architecture," Microporous and Mesoporous Materials, vol. 96, no. 1-3, pp. 44-54, 2006.

[15] X. Gao and J. Xu, "A new application of clay-supported vanadium oxide catalyst to selective hydroxylation of benzene to phenol," Applied Clay Science, vol. 33, no. 1, pp. 1-6, 2006.

[16] K. V. Bineesh, M.-I. Kim, G.-H. Lee, M. Selvaraj, and D.-W. Park, "Catalytic performance of vanadia-doped alumina-pillared clay for selective oxidation of H2S," Applied Clay Science, vol. 74, pp. 127-134, 2013.

[17] M. Yin, S. He, Z. Yu, K. Wu, L. Wang, and C. Sun, "Effect of alumina support on catalytic performance of $\mathrm{Pt}-\mathrm{Sn} / \mathrm{Al} 2 \mathrm{O} 3$ catalysts in one-step synthesis of N-phenylbenzylamine from aniline and benzyl alcohol," Chinese Journal of Catalysis, vol. 34, no. 8, pp. 1534-1542, 2013.

[18] T. P. Braga, A. N. Pinheiro, E. R. Leite, R. C. R. dos Santos, and A. Valentini, " $\mathrm{Cu}, \mathrm{Fe}$, or Ni doped molybdenum oxide supported on $\mathrm{Al}_{2} \mathrm{O}_{3}$ for the oxidative dehydrogenation of ethylbenzene," Chinese Journal of Catalysis, vol. 36, pp. 712-720, 2015.

[19] K.-W. Park, H. J. Seo, and O.-Y. Kwon, "Mesoporous silicapillared titanosilicate as catalytic support for partial oxidation of methane," Microporous and Mesoporous Materials, vol. 195, pp. 191-196, 2014.

[20] A. Patel, P. Shukla, T. Rufford et al., "Catalytic reduction of NO by CO over copper-oxide supported mesoporous silica," Applied Catalysis A: General, vol. 409-410, pp. 55-65, 2011.

[21] T. P. Braga, A. N. Pinheiro, W. T. Herrera, Y. T. Xing, E. BaggioSaitovitch, and A. Valentini, "Synthesis and characterization of iron oxide nanoparticles dispersed in mesoporous aluminum oxide or silicon oxide," Journal of Materials Science, vol. 46, no. 3, pp. 766-773, 2011.

[22] P. G. Savva, K. Goundani, J. Vakros et al., "Benzene hydrogenation over $\mathrm{Ni} / \mathrm{Al} 2 \mathrm{O} 3$ catalysts prepared by conventional and solgel techniques," Applied Catalysis B: Environmental, vol. 79, no. 3, pp. 199-207, 2008.

[23] M. Cris, M. Raileanu, M. Jitianuc, A. Rusua, G. Sadanandamb, and J. K. Reddy, "Sol-gel based alumina powders with catalytic applications," Applied Surface Science, vol. 258, pp. 448-455, 2011.

[24] T. P. Braga, B. M. C. Sales, A. N. Pinheiro, W. T. Herrera, E. Baggio-Saitovitch, and A. Valentini, "Catalytic properties of cobalt and nickel ferrites dispersed in mesoporous silicon oxide for ethylbenzene dehydrogenation with CO2," Catalysis Science \& Technology, vol. 1, no. 8, pp. 1383-1392, 2011.

[25] T. P. Braga, E. C. C. Gomes, A. F. D. Sousa, N. L. V. Carreño, E. Longhinotti, and A. Valentini, "Synthesis of hybrid mesoporous spheres using the chitosan as template," Journal of NonCrystalline Solids, vol. 355, no. 14-15, pp. 860-866, 2009.

[26] A. B. Sifontes, G. Gonzalez, J. L. Ochoa, L. M. Tovar, T. Zoltan, and E. Cañizales, "Chitosan as template for the synthesis of ceria nanoparticles," Materials Research Bulletin, vol. 46, no. 11, pp. 1794-1799, 2011. 
[27] Y. Matsumura, "Stabilization of $\mathrm{Cu} / \mathrm{ZnO} / \mathrm{ZrO} 2$ catalyst for methanol steam reforming to hydrogen by coprecipitation on zirconia support," Journal of Power Sources, vol. 238, pp. 109116, 2013.

[28] S. S.-Y. Lin, H. Daimon, and S. Y. Ha, "Co/CeO2-ZrO2 catalysts prepared by impregnation and coprecipitation for ethanol steam reforming," Applied Catalysis A: General, vol. 366, no. 2, pp. 252-261, 2009.

[29] S. S. Fortes, J. G. S. Duque, and M. A. Macêdo, "Nanocrystals of BaFe12O19 obtained by the proteic sol-gel process," Physica B: Condensed Matter, vol. 384, no. 1-2, pp. 88-90, 2006.

[30] P. C. A. Brito, R. F. Gomes, J. G. S. Duque, and M. A. Macêdo, "SrFe12O19 prepared by the proteic sol-gel process," Physica B: Condensed Matter, vol. 384, no. 1-2, pp. 91-93, 2006.

[31] B. F. Dos Santos, R. M. Araujo, M. E. G. Valerio, and M. V. D. S. Rezende, "Optical spectroscopy study of YVO4:Eu3+ nanopowders prepared by the proteic sol-gel route," Solid State Sciences, vol. 42, pp. 45-51, 2015.

[32] N. A. S. Nogueira, E. B. da Silva, P. M. Jardim, and J. M. Sasaki, "Synthesis and characterization of NiAl2O4 nanoparticles obtained through gelatin," Materials Letters, vol. 61, no. 25, pp. 4743-4746, 2007.

[33] T. P. Braga, D. F. Dias, M. F. de Sousa, J. M. Soares, and J. M. Sasaki, "Synthesis of air stable FeCo alloy nanocrystallite by proteic sol-gel method using a rotary oven," Journal of Alloys and Compounds, vol. 622, pp. 408-417, 2015.

[34] C. Yang, L. Xu, Y. Zhou et al., "A green fabrication approach of gelatin/CM-chitosan hybrid hydrogel for wound healing," Carbohydrate Polymers, vol. 82, no. 4, pp. 1297-1305, 2010.

[35] D. Yang, Y. Li, and J. Nie, "Preparation of gelatin/PVA nanofibers and their potential application in controlled release of drugs," Carbohydrate Polymers, vol. 69, no. 3, pp. 538-543, 2007.

[36] M. Peter, N. Ganesh, N. Selvamurugan et al., "Preparation and characterization of chitosan-gelatin/nanohydroxyapatite composite scaffolds for tissue engineering applications," Carbohydrate Polymers, vol. 80, no. 3, pp. 687-694, 2010.

[37] N. Ktari, M. Jridi, R. Nasri et al., "Characteristics and functional properties of gelatin from zebra blenny (Salaria basilisca) skin," LWT-Food Science and Technology, vol. 58, no. 2, pp. 602-608, 2014.

[38] Z. Zarai, R. Balti, H. Mejdoub, Y. Gargouri, and A. Sayari, "Process for extracting gelatin from marine snail (Hexaplex trunculus): Chemical composition and functional properties," Process Biochemistry, vol. 47, no. 12, pp. 1779-1784, 2012.

[39] A. A. Karim and R. Bhat, "Fish gelatin: properties, challenges, and prospects as an alternative to mammalian gelatins," Food Hydrocolloids, vol. 23, no. 3, pp. 563-576, 2009.

[40] Numerical data, 2017 http://www.prnewswire.com/newsreleases/global-gelatin-market-is-expected-to-reach-usd-279billion-in-2018-transparency-market-research-213992871.html.

[41] A. E. Kadib, K. Molvinger, T. Cacciaguerra, M. Bousmina, and D. Brunel, "Chitosan templated synthesis of porous metal oxide microspheres with filamentary nanostructures," Microporous and Mesoporous Materials, vol. 142, no. 1, pp. 301-307, 2011.

[42] W.-B. Wang, D.-J. Huang, Y.-R. Kang, and A.-Q. Wang, "Onestep in situ fabrication of a granular semi-IPN hydrogel based on chitosan and gelatin for fast and efficient adsorption of $\mathrm{Cu} 2+$ ion," Colloids and Surfaces B: Biointerfaces, vol. 106, pp. 51-59, 2013.
[43] S. Smitha, P. Shajesh, P. Mukundan, T. D. R. Nair, and K. G. K. Warrier, "Synthesis of biocompatible hydrophobic silicagelatin nano-hybrid by sol-gel process," Colloids and Surfaces B: Biointerfaces, vol. 55, no. 1, pp. 38-43, 2007.

[44] M. Wannaborworn, P. Praserthdam, and B. Jongsomjit, "A comparative study of solvothermal and sol-gel-derived nanocrystalline alumina catalysts for ethanol dehydration," Journal of Nanomaterials, vol. 2015, Article ID 519425, 11 pages, 2015.

[45] T. Inmanee, P. Pinthong, and B. Jongsomjit, "Effect of calcination temperatures and mo modification on nanocrystalline $(\gamma$ $\chi$ )-Al2O3 catalysts for catalytic ethanol dehydration," Journal of Nanomaterials, vol. 2017, Article ID 5018384, 2017.

[46] C.-W. Chu, Y.-C. Huang, C.-C. Tsai, and J.-T. Chen, "Wetting in nanopores of cylindrical anodic aluminum oxide templates: Production of gradient polymer nanorod arrays on large-area curved surfaces," European Polymer Journal, vol. 63, pp. 141-148, 2015.

[47] H.-P. Hentze and M. Antonietti, "Template synthesis of porous organic polymers," Current Opinion in Solid State \& Materials Science, vol. 5, no. 4, pp. 343-353, 2001.

[48] P. Escalé, L. Rubatat, L. Billon, and M. Save, "Recent advances in honeycomb-structured porous polymer films prepared via breath figures," European Polymer Journal, vol. 48, no. 6, pp. 1001-1025, 2012.

[49] M. T. P. da Silva, J. C. Carvalho, S. B. C. Pergher, and T. P. Braga, "Carboxymethylcellulose template synthesis of porous aluminium oxide from hybrid spheres: influence of the degree of substitution and polymerization," Journal of Porous Materials, vol. 23, no. 3, pp. 811-822, 2016. 

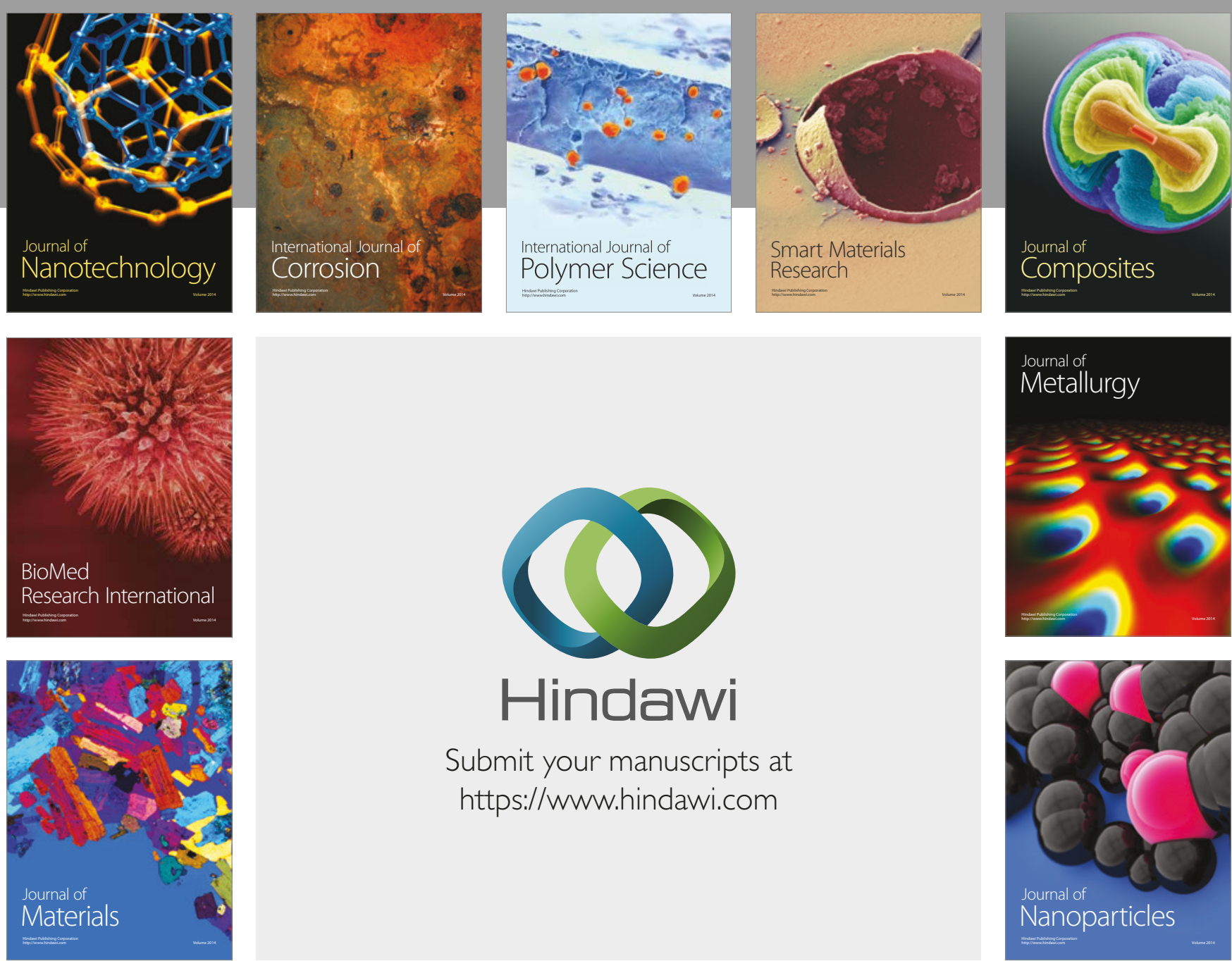

\section{Hindawi}

Submit your manuscripts at

https://www.hindawi.com
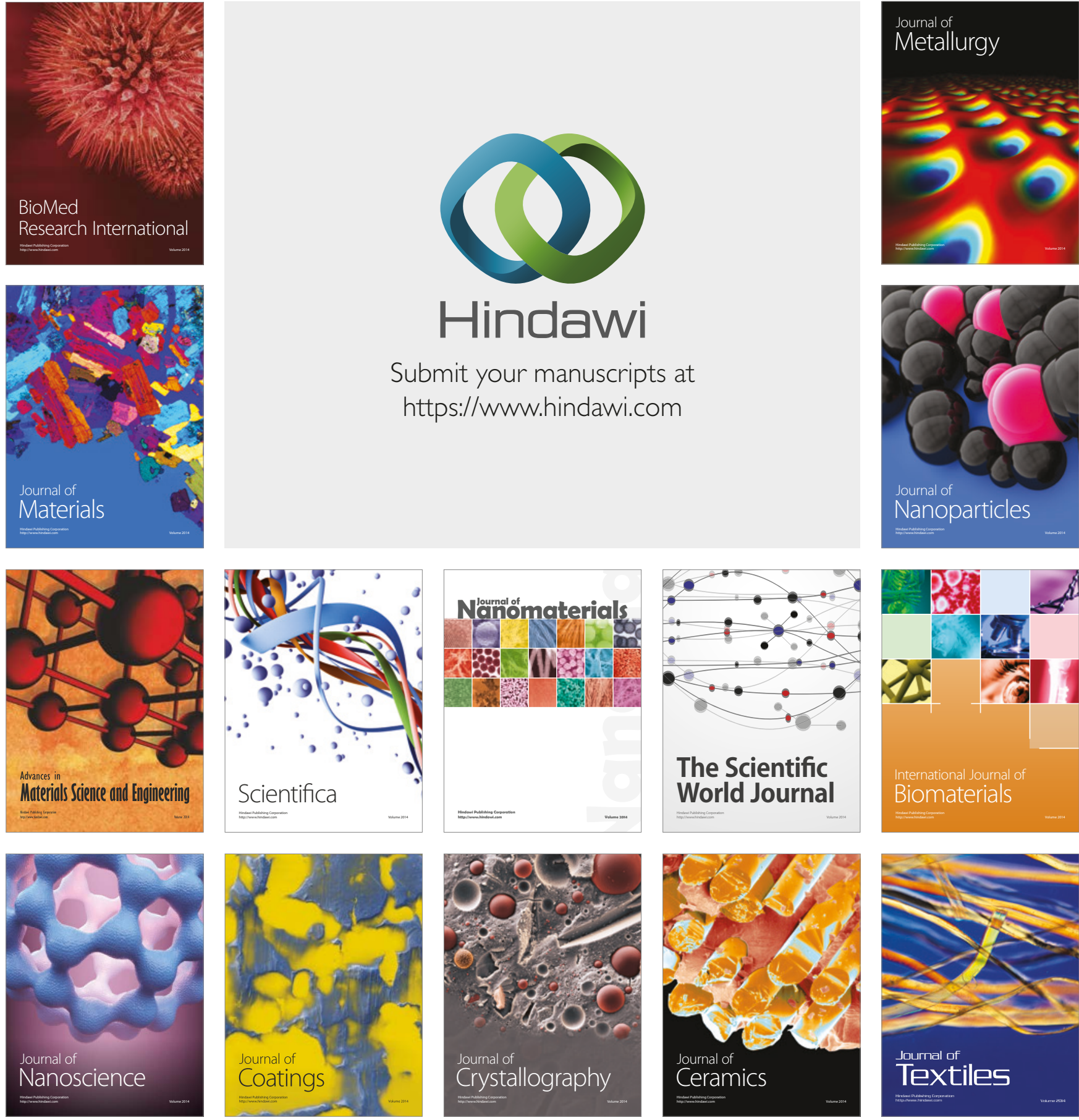

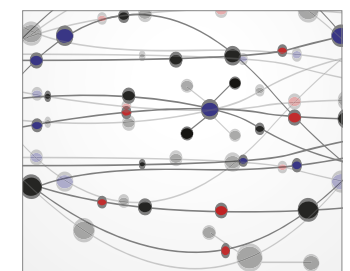

The Scientific World Journal
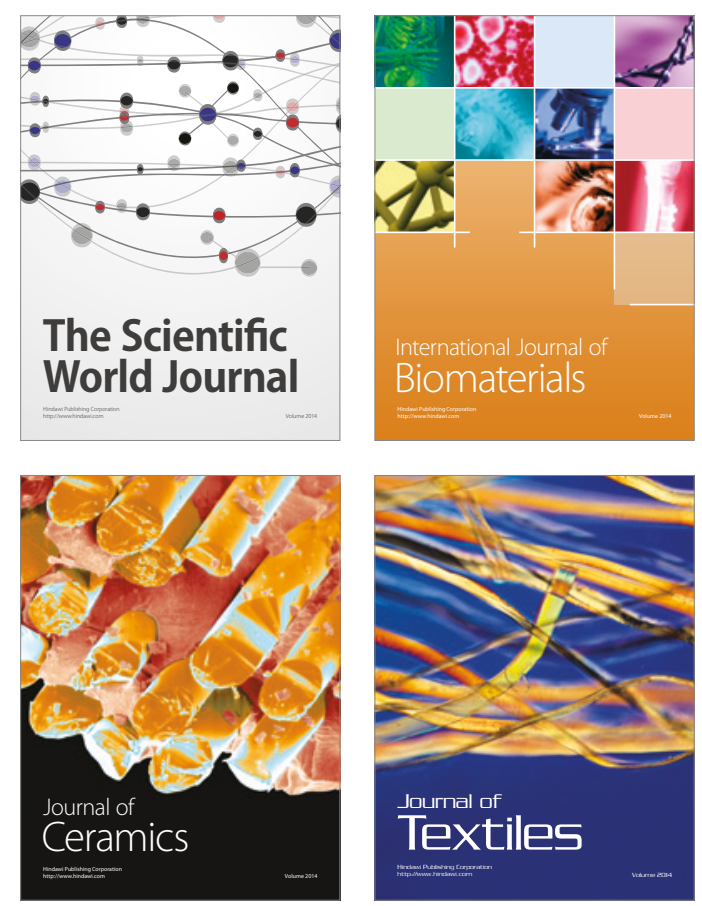